\title{
SEISMIC VULNERABILITY ASSESSMENT OF A HISTORIC BRICK MASONRY BUILDING BY FRAGILITY FUNCTIONS
}

\author{
KULTIGIN DEMIRLIOGLU ${ }^{1 *}$ AND SERDAR SOYOZ ${ }^{2}$ \\ ${ }^{1}$ Department of Civil Engineering and Energy Technology \\ Oslo Metropolitan University \\ Pilestredet 35, 0166 Oslo, Norway \\ e-mail: kultigin@oslomet.no, (*corresponding author) \\ ${ }^{2}$ Civil Engineering Department \\ Boğaziçi University \\ South Campus/ Bebek, 34342 İstanbul, Turkey \\ email: serdar.soyoz@boun.edu.tr,www.shm.ce.boun.edu.tr/
}

Keywords: Seismic Fragility Curve, Incremental Dynamic analysis, Vulnerability Assessment

\begin{abstract}
This paper aims at contributing to the seismic vulnerability assessment of a historic brick masonry building constructed in Istanbul by comparison of the derived analytical and empirical fragility functions. For this purpose, Incremental Dynamic Analysis for each ground motion record was initially performed by series of Nonlinear Time History Analyses on the most vulnerable façade of the case study building modelled using Equivalent Frame Method. By scaling the PGA values of the fifteen earthquake records selected from PEER NGA West2 Data Base, it was aimed to observe the structural response corresponding the all limit states from yield point to collapse and identify each PGA causing the structure to reach these limit states. Herein, PGA and Spectral Displacements were considered as the seismic intensity parameters, and the ultimate storey drifts were referred as Engineering Demand Parameter. Both analytical and empirical seismic fragility functions were derived using lognormal probability distribution. Consequently, the obtained analytical fragility curves for vulnerability assessment of the building were compared with the fragility curves derived according to European (RISK-UE), HAZUS and Istanbul Building Taxonomies for the same building classification with the case study building in attempt to investigate the concordance of the results.
\end{abstract}




\section{INTRODUCTION}

The recent studies regarding seismic risk analysis have revealed that unreinforced masonry buildings are the most seismically vulnerable building type, which constitutes a significant percentage of the existing building stock all over the world. Their high vulnerability to seismic events and aggressive environmental conditions arises a substantial need for improving the knowledge of their seismic behaviour, and developing analytical and numerical models for their risk assessment. Seismic vulnerability refers to the structural susceptibility to damage or loss due to a seismic activity. It can be identified by means of fragility functions, giving the likelihood of reaching or exceeding a certain limit state as a function of the Intensity Measure (IM) such as Peak Ground Acceleration (PGA), Peak Ground Velocity (PGV), Spectral displacement $\left(\mathrm{S}_{\mathrm{d}}\right)$, etc. or using vulnerability functions, providing the expected value of loss. [1].

In literature, there have been a wide range of studies carried out on vulnerability assessment and derivation of fragility functions since the existence of complex structural typologies leads to a very demanding task including a high amount of uncertainty in the characterization of the structural members, as well as the mechanical properties of the constituent materials particularly for masonry structures [2]. Some researchers have made substantial contributions to the inherent probabilistic nature of the seismic risk assessment, developing distinctive methodologies such as RISK-UE, SYNER-G and PERPETUATE to derive seismic fragility functions for common and cultural heritage masonry buildings in consideration of load bearing

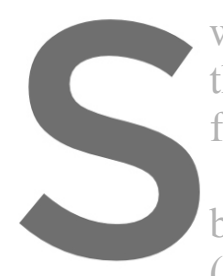
wall material, the number of stories, different building taxonom
these, empirical, analytical, expert judgement and hybrid-bas
fragility functions were developed [8-10].
This paper presents the vulnerability evaluation of a historica
back to the 1920 s. The probability distribution of the - seismic (limited damage, significant damage and near collapse) is obtained performing Incremental Dynamic Analyses (IDA) under 15 different earthquake records. By using PGA and $\mathrm{S}_{d}$ as

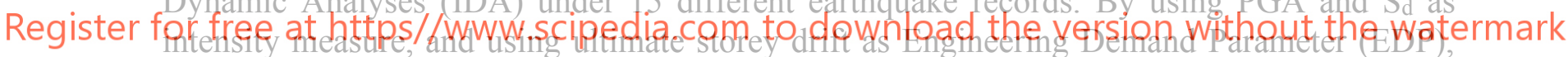

both empirical and analytical seismic fragility curves are derived, employing the lognormal probability distribution. Therefore, the obtained fragility curves provide information regarding the likelihood of occurrence and exceeding of each damage level that the building may experience under the seismic actions induced. Via the comparison of the results obtained from the empirical fragility curves when the analytical fragility curve is taken as a reference, this study finally points out which fragility curve parameters proposed by RISK-UE, HAZUS, and ISTANBUL can be more convenient to be used for vulnerability assessment of the taxonomy of old-brick masonry buildings representing the case study building.

\section{CASE STUDY BUILDING}

A historic building built in 1925 in Istanbul is registered in the cultural heritage list by Turkish Republic Ministry of Culture and Tourism. In the scope of this study, seismic vulnerability assessment was carried out to determine the current health condition of this building [11]. The building symbolizes a specific typology of the traditional Turkish historical building architecture in the early 20th century. It consists of three storeys with different heights $3.45 \mathrm{~m}, 4.84 \mathrm{~m}$ and $4.45 \mathrm{~m}$ belonging to basement, ground and first storeys, respectively. With 
respect to the load-bearing system, the walls are made of solid bricks and Khorasan mortar which is a widely used local mortar in the construction of historical masonry structures in Turkey and commonly includes hydraulic lime, kaolin, calcite, refined Khorasan clay, etc. The slabs of ground floor and first floor consist of brick arch floor systems, where the steel beams of INP180 are installed with an interval of $60 \mathrm{~cm}$, and the roof slab is made of oak timber elements. The wall thicknesses vary between $68-88 \mathrm{~cm}$ in the basement, $45-76 \mathrm{~cm}$ in the ground floor, and $32-65 \mathrm{~cm}$ in the first floor. More detail about the building geometry and the mechanical property of the material used can be found in [12].
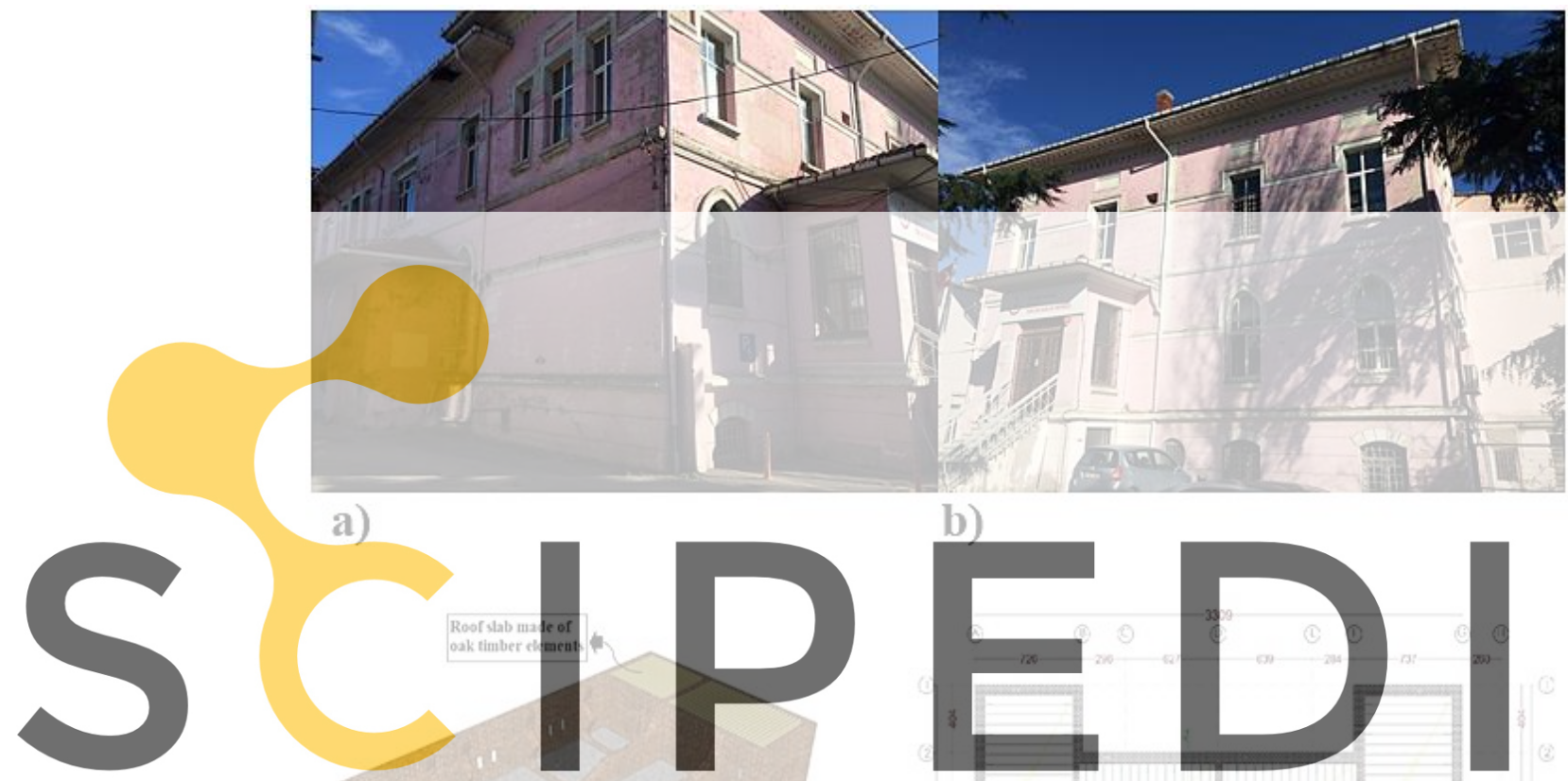

a)
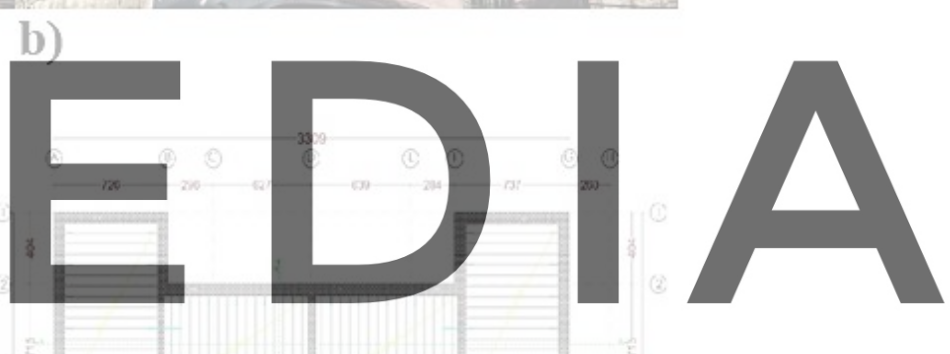

Register for free at https//www.scipedia.com to download the version without the watermark

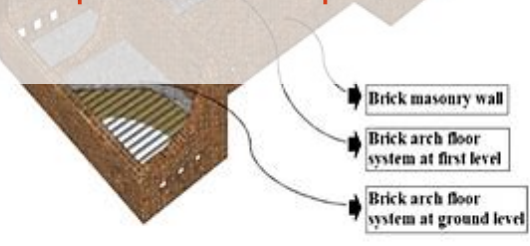

c)

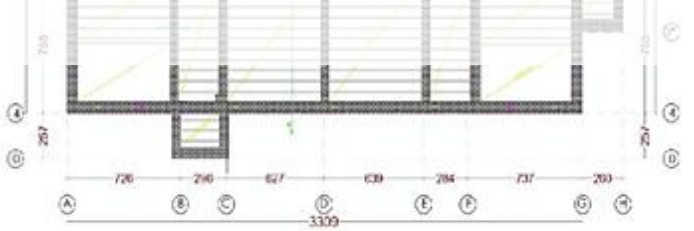

d)

Figure 1: (a) Corner view (b) front view (c) illustration of the load-bearing system of the URM building and (d) plan of the ground floor.

In-situ investigation showed that the connection of intersecting walls and clamping between bearing walls and floor systems were in good condition. No local damages and cracking between bearing wall and the floor system have been detected. The presence of proper connections in the existing property made us consider that the connections would prevent outof-plane behaviour; therefore, only in-plane behaviour was considered in this study. 


\section{NUMERICAL MODELING OF THE HISTORICAL BUILDING}

In the literature, for masonry walls, there have been a various type of modelling techniques such as Rigid Body and Spring Model, Fibber Contact Element Method, Applied Element Method etc. However, in this study, the 3D Finite Element Model (FEM), the most frequently used method, was adopted for generation of the numerical model of the building. Initially, the linear dynamic analysis was performed using FEM so as to carry out a general assessment procedure in terms of the stress and displacement demands occurring under the design earthquake. As a result of the linear dynamic analysis, it was detected that both right and front façades governed the collapse state of the URM structure in terms of the limit states. However, the front façade was the most vulnerable one in terms of principal and shear stresses exceeding their threshold values due to having more openings, compared to the right façade. Therefore, 2D Equivalent Frame (EF) model of the front façade was generated by adopting the criterion proposed by Dolce (1991). In the light of in-situ observations, which provide a basis for the assumption of the bearing walls properly connected to the floor, only in-plane behaviour was deemed in analyses to accurately simulate the global response of the structure. The EF method simplifies modelling masonry walls with frame elements via consideration of the homogeneous and isotropic material idealization and defining the nonlinear behaviour of structural masonry. For generating seismic fragility curves that will be used in vulnerability assessment procedure of the building, as a nonlinear dynamic method, a set of Nonlinear Time History analyses (NLTHA) was employed to perform series of simulations. In an attempt to diminish dissipation

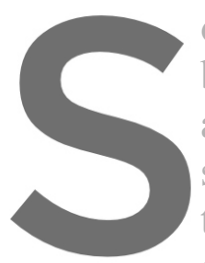
of time and computationa by the definition of sher and G. M. Calvi (1997) shear either in diagonal than other in-plane
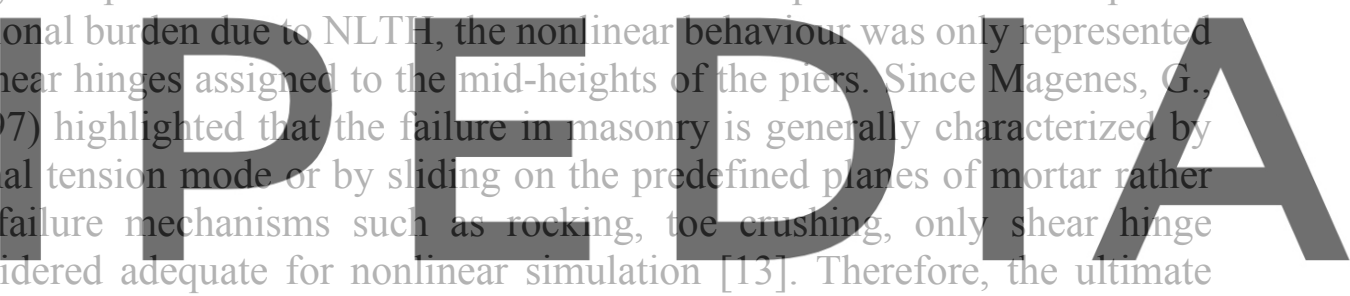
resistance was controlled by the shear failure and the shear failure was controlled by the shear

to the achievement of the ultimate drift $\delta \mathrm{u}$ which is assumed to be $0.4 \%$ of the effective height of the pier [14]. Please note that the effective height of the pier was changed to $0.5 \%$ in 2018 with the new version of the standard (NTC, 2018) [15].

According to Eurocode 8 Part 3 (EN 1998-3 2005), the limit states of URM walls were determined, which correspond to the attainment of the global displacement capacity on the pushover curve [16]. The ultimate displacement capacity is described as the top displacement, and three limit states exist on the pushover curve in terms of top displacement, as follows.

- Limit state of Limited Damage (LD) is where the structure yields on the curve of idealized elasto-perfectly plastic force/displacement relationship.

- Limit state of Significant Damage (SD) is equal to 3/4 of the top displacement capacity corresponding the total base shear.

- Limit state of Near Collapse (NC) is equal to below 80 percent of the peak resistance of the structure.

Structural collapse was assumed once the in-plane deformation capacity of piers was firstly reached due to the ultimate shear displacement controlled by shear hinges. 


\section{VULNERABILITY ASSESSMENT}

\subsection{Incremental Dynamic Analysis}

Incremental dynamic analysis (IDA) is a computational analysis method for performing a comprehensive assessment of the behaviour of structures under seismic loads, which reveals the structural response from linear range to nonlinear range leading to collapse. It has been utilized to rely on the results of probabilistic seismic hazard analysis in attempt to evaluate the seismic risk confronted by a given structure [17]. IDA comprises performing numerous nonlinear dynamic analyses of a structural model under a set of ground motion records. Each record should be properly scaled to several levels of seismic intensity to enable structures to cover the entire range of structural response from elastic to inelastic and ultimately to global dynamic instability where the structures no longer resist. Moreover, the selection of earthquake inputs is a momentous phase to acquire reliable results regarding vulnerability assessment, since a seismic action can alter with regards to the frequency content, the energy content and duration, which lead to different effects on the same structure. For this purpose, 15 earthquake records were advertently selected from PEER NGA West2 Data Base in accordance with the design response spectrum generated as shown in Figure 2.
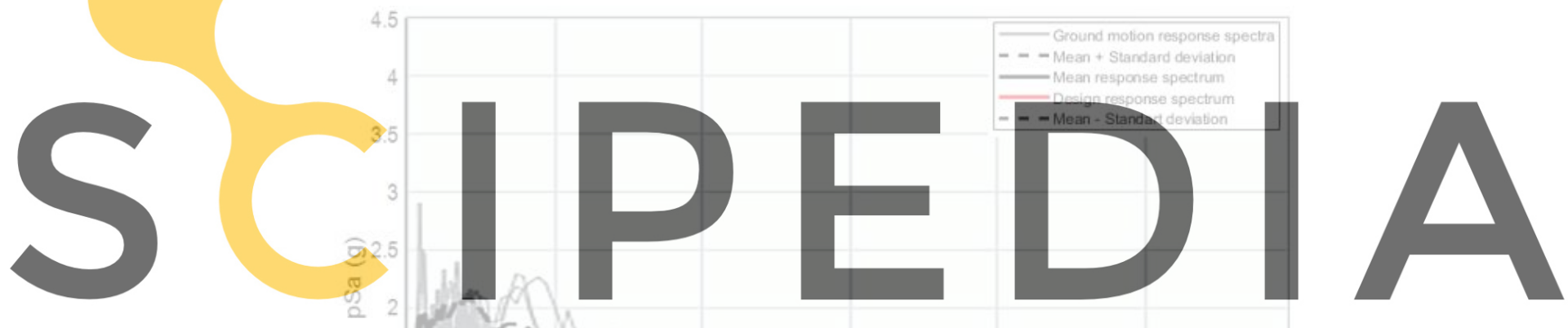

Register for free at https//www.scipedia.com to download the version without the watermark

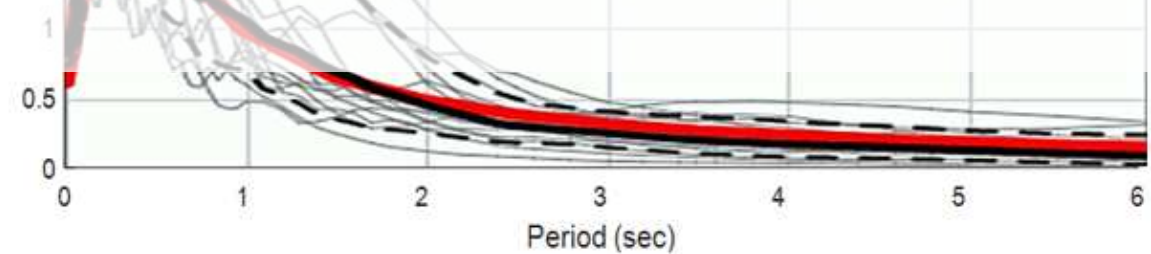

Figure 2: Spectra of selected ground motions.

In this study, PGA values were used as an Intensity Measure (IM) that characterizes the conditional probability of attaining a given damage state for a given hazard level. By scaling the PGA values, it is aimed at leading the structure to reach all limit states from yield point to collapse. As a result of scaling procedures, each PGA value being a component of the total 15 scenario earthquakes, which caused the building to reach the limit states of limited damage, significant damage and near collapse were identified (Figure 3). Engineering Demand Parameters (EDP), which are measures of the structural response were represented by the ultimate drift. 


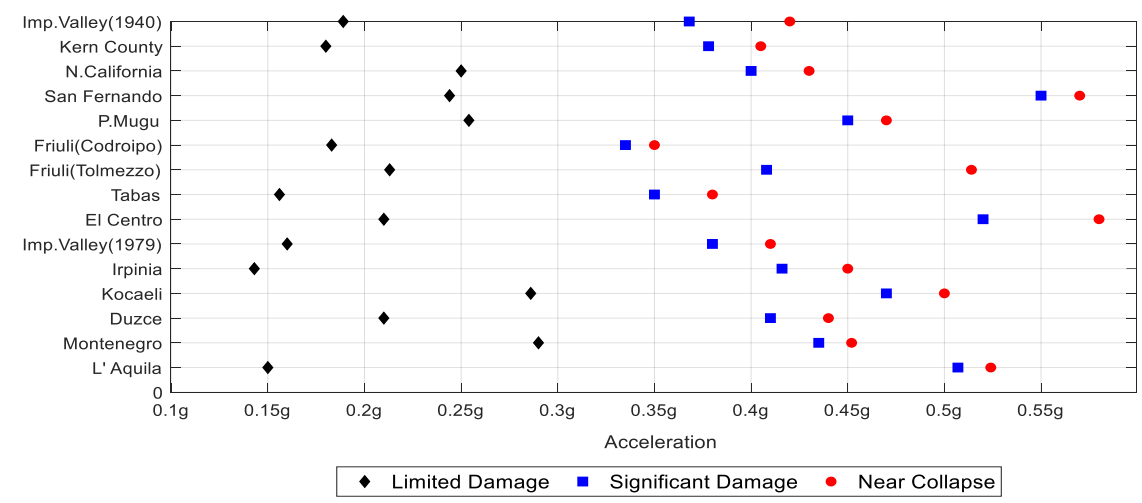

Figure 3: Summary of PGA values leading the structure to reach LD, SD and NC limit states.

\subsection{Seismic Fragility Curve}

In seismic risk assessment, vulnerability curves are frequently used to identify the probability that structures at risk will withstand different levels of loss under a series of earthquake ground motion intensities. These vulnerability curves can be generated using the empirical approaches based on statistical analysis of loss values observed in past earthquakes, analytical or numerical approaches, and hybrid approaches that are combination of these methodologies and expert opinion [18]. For the purposes of vulnerability assessment, fragility curves are gaining more importance as a statistical tool which establishes the relationship between the likelihood of reaching or exceeding a specified level of damage and the effects of the projected ground inotions on the built environment. In this study, the generation of fragility curves will cover anatical and empirical approaches by use of lognomal distribution for the vulnerability assessment of the case study building. The resulting datasets, used in loghormal distribution for constructing the analytical fragility curves, were obtained considering only the

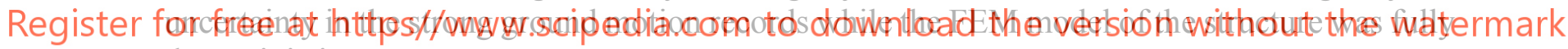
deterministic.

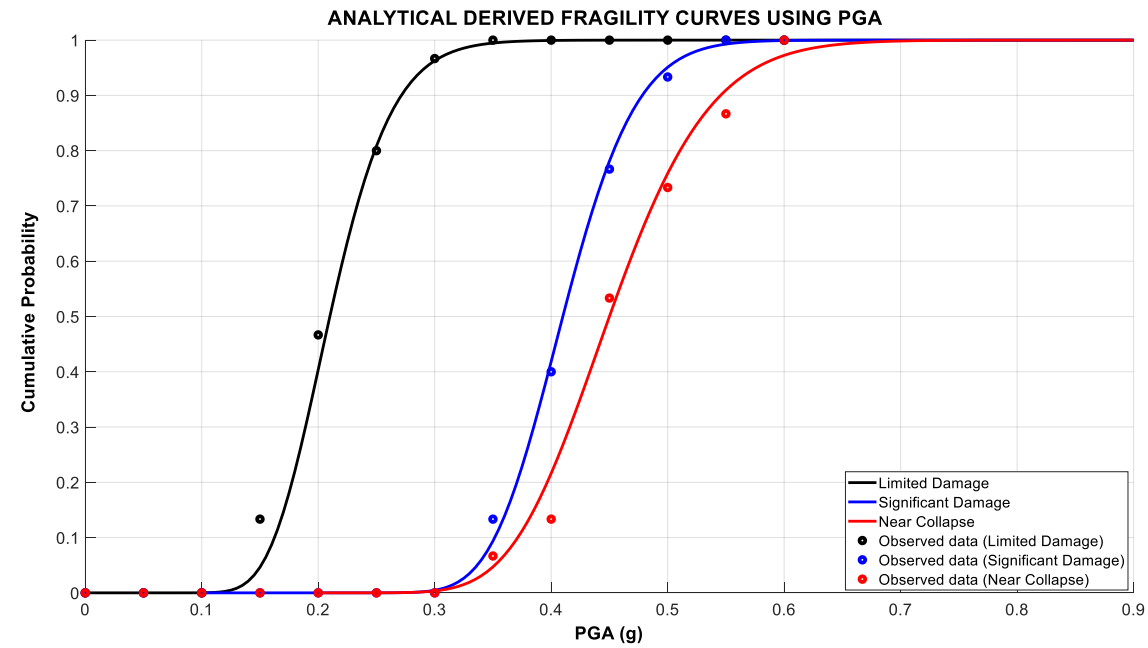

Figure 4: Analytical derived fragility curves based on the PGAs leading the structure to reach LD, SD and NC. 
Using the PGA values leading the structure to reach LD, SD and NC limit states presented in Figure 3, the analytical fragility curves were derived as shown in Figure 4. By employing lognormal distributions in calculations, the obtained fragility curves properly fitted the observed data. Therefore, they provided an opportunity to assess the seismic vulnerability by direct comparison with the subjected PGA values. It showed that when the case study building is subjected to the strong ground motions with the PGA values slightly more than $0.2 \mathrm{~g}$ and 0.4 $\mathrm{g}$, it will experience limited and significant damages, respectively, with an exceedance probability of $50 \%$ while a PGA of $0.45 \mathrm{~g}$ will be a sufficient intensity to reach the limit state of near collapse for the same exceedance probability. Regarding empirically derived fragility curves, they were generally represented through spectral displacements as IM. Moreover, herein, the fragility curves obtained from empirical approaches will be compared to each other and interrogated to clarify whether they can be addressed to the vulnerability assessment of a single case study building in a specific taxonomy even though in practice they are to be used in the seismic risk assessment of a specific building stock at a certain location.

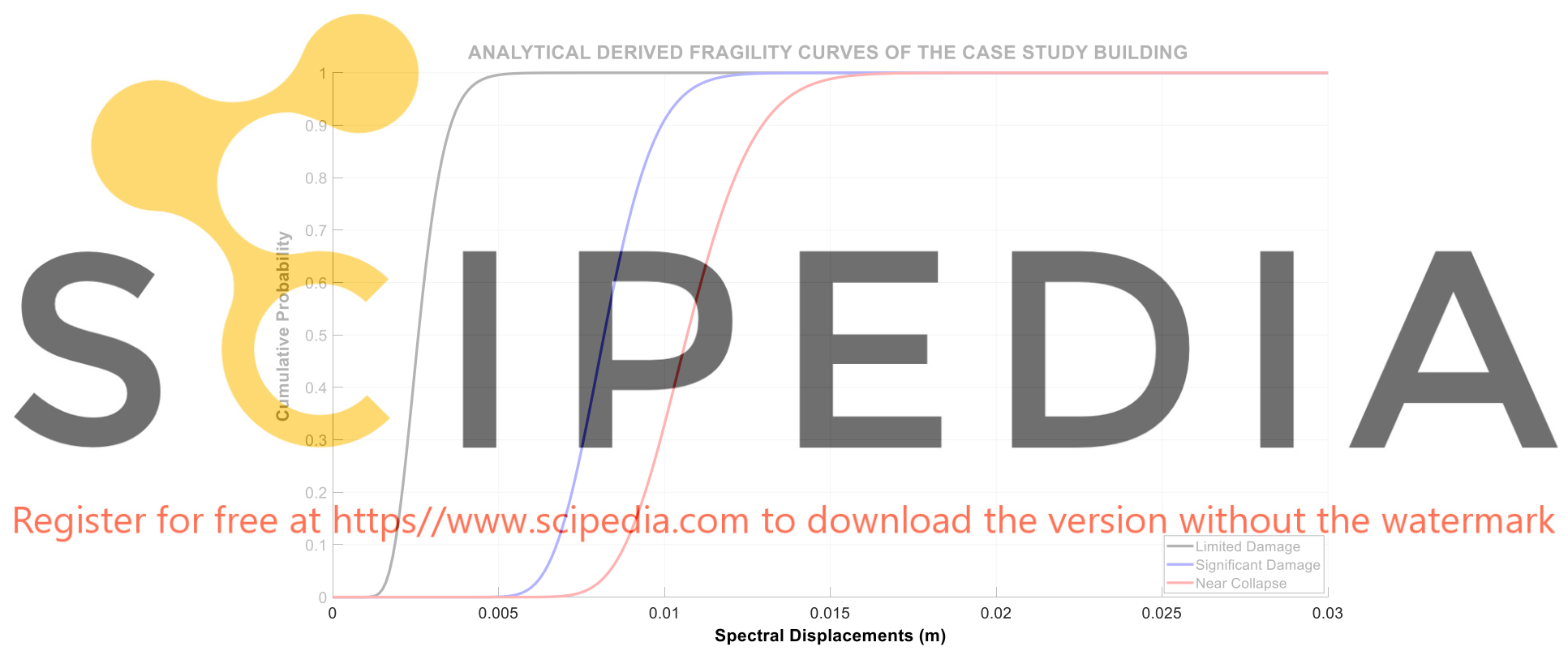

Figure 5: Analytical derived fragility curves of the case study building using Spectral Displacements.

Thorough the IDAs, each spectral displacement was identified for a certain damage level. The analytical fragility curves were generated on the basis of spectral displacements (Figure 5). Since the case study building is a type of 2-storey brick masonry building constructed in 1925, in literature its taxonomy is equivalent to M5- $\mathbf{L}$ according to European Building Taxonomy [19] representing Unreinforced Masonry (old bricks), URML according to pre-code buildings of HAZUS 99 Building Taxonomy [20-21] representing Unreinforced Masonry Bearing Walls, and B211 according to Istanbul Building Taxonomy [22] representing 1-4 storey masonry buildings (built in pre 1979). The fragility curve parameters of the empirical approaches mentioned were presented in Table 1 where $S_{d}$ is the median value of the lognormal distribution of the intensity measure (spectral displacement) and $\beta$ is the dispersion related to the uncertainties in the seismic demand. 
Table 1: Fragility curve parameters.

\begin{tabular}{lcccccc}
\hline & $\begin{array}{c}\text { Limited Damage } \\
\text { (Slight) }\end{array}$ & \multicolumn{2}{c}{$\begin{array}{c}\text { Significant Damage } \\
\text { (Moderate) }\end{array}$} & \multicolumn{2}{c}{$\begin{array}{c}\text { Near Collapse } \\
\text { (Extensive) }\end{array}$} \\
\cline { 2 - 7 } Building Taxonomy & $\mathbf{S}_{\mathbf{d}, \mathbf{s}(\mathbf{m})}$ & $\boldsymbol{\beta}_{\mathbf{s}}$ & $\mathbf{S}_{\mathbf{d}, \mathbf{m}(\mathbf{m})}$ & $\boldsymbol{\beta}_{\mathbf{m}}$ & $\mathbf{S}_{\mathbf{d}, \mathbf{e}}(\mathbf{m})$ & $\boldsymbol{\beta}_{\mathbf{e}}$ \\
\hline EUROPE (M5-L) & 0.0013 & 1.07 & 0.0029 & 1.07 & 0.006 & 1.07 \\
\hline HAZUS (URML) & 0.0081 & 1.15 & 0.0165 & 1.19 & 0.0411 & 1.2 \\
\hline ISTANBUL (B211) & 0.0135 & 0.99 & 0.0315 & 1.05 & 0.072 & 1.1 \\
\hline
\end{tabular}

FRAGILITY CURVE COMPARISON OF EUROPE, HAZUS AND ISTANBUL

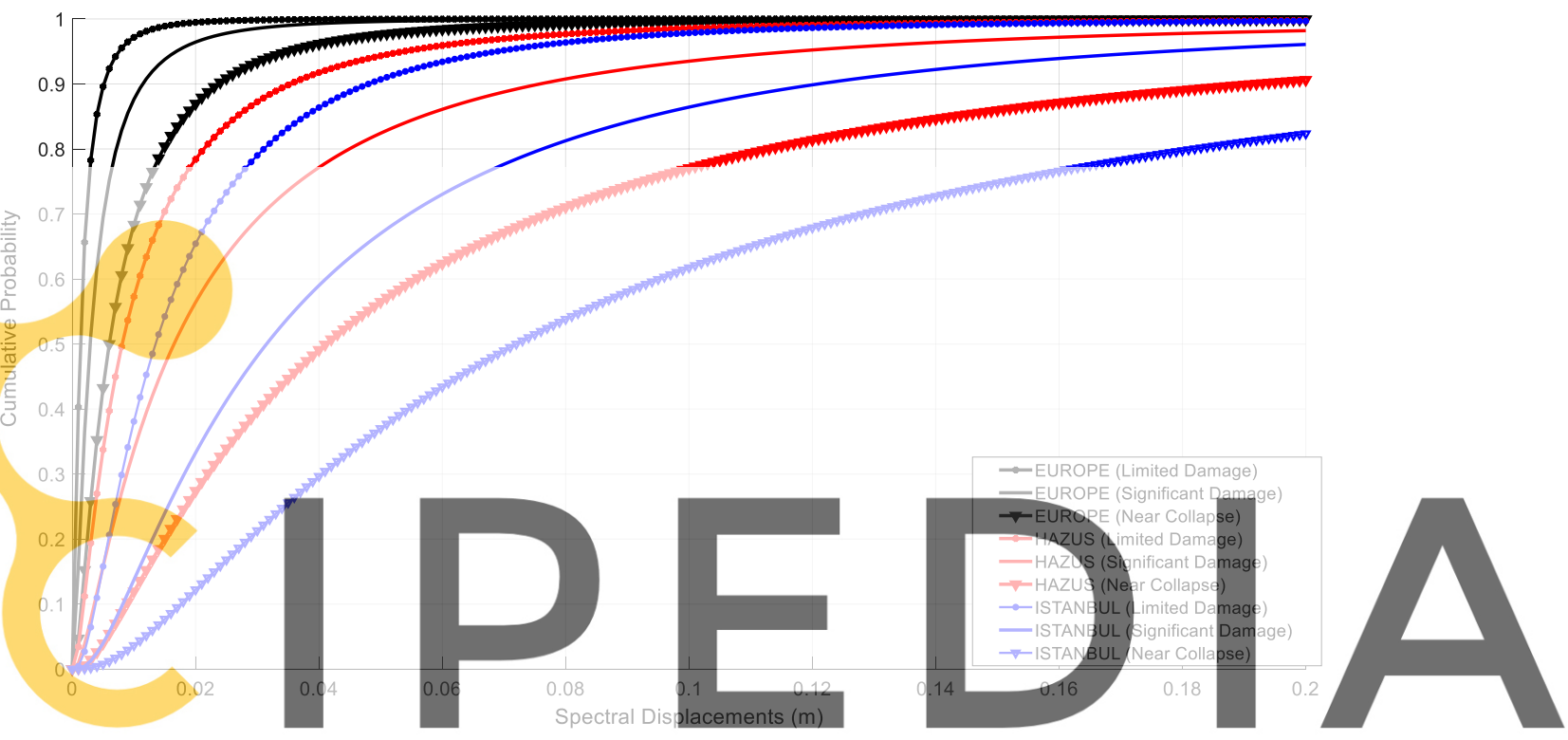

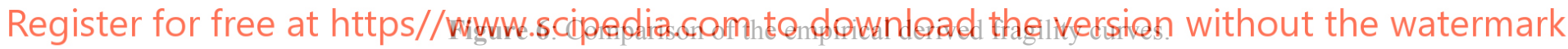

In Figure 6, the obtained empirical fragility curves for the same taxonomy with the case study building were compared. As it can be seen from the figure, fragility curves derived from HAZUS and Istanbul building taxonomy demonstrate relatively close behaviour and their spectral displacement demands anticipated for the limited damage underestimate the spectral displacement demands corresponding to the limit state of near collapse by European building taxonomy (RISK-UE). In other words, if the building is subjected to a spectral displacement demand of $20 \mathrm{~mm}$, it will experience the limit state of the near collapse with a probability of approximately $90 \%$ according to RISK UE, whereas it is expected to reach the collapse probabilities of $15 \%$ and $25 \%$ for the same level of the IM according to ISTANBUL and HAZUS, respectively. When considering the structural response of the case study building based on the results obtained from the analytical fragility curves in Figure 5, the building reaches a complete collapse under earthquake-shaking intensity of a $20 \mathrm{~mm}$-spectral displacement. As a result of the vulnerability assessment via the fragility functions derived from the analytical and RISK UE based empirical approaches, it can be concluded that they are more coherent in terms of the anticipated cumulative probabilities corresponding to IM for the given damage levels (Figure 7). 


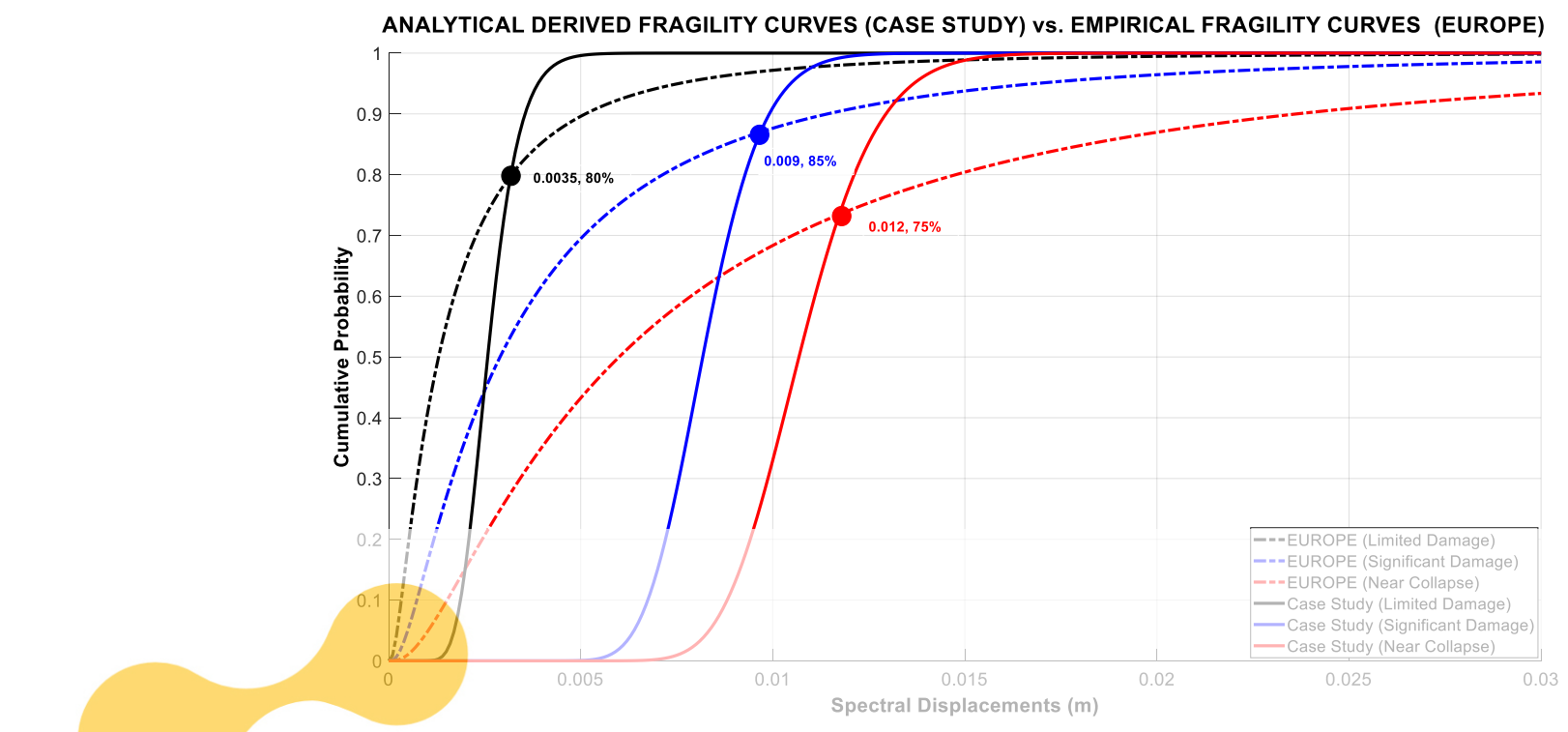

Figure 7: Comparison of the analytical derived fragility curves of the case study building and the empirical

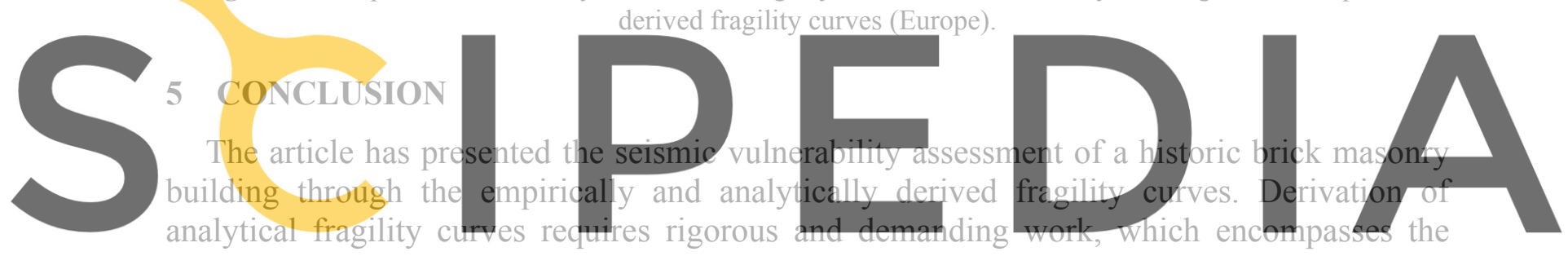

implementation of IDAs to determine the IM levels causing the occurrence and non-occurrence

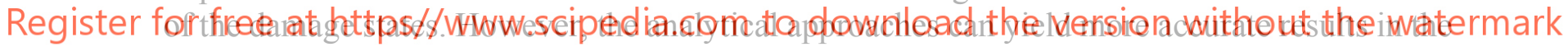
estimation of vulnerability since they are directly derived from the structural analysis of the objective buildings. As an alternative to use of this computationally expensive procedure, the effectiveness of the empirically derived fragility curves has been questioned so as to see the possibility of their application in the vulnerability assessment of a single building, whereas in practice they are utilized for the seismic risk assessment of a certain building inventory in a specific location. By means of the comparison of the results obtained from the empirical fragility curves when the analytical fragility curve is taken as a reference, it has been observed that RISK-EU produces the closest result in terms of the anticipated cumulative probabilities for the given damage levels. Moreover, the spectral displacement demands, causing the limited damage, proposed by HAZUS and ISTANBUL strikingly exceed the required spectral intensity for near collapse by RISK-EU. For the masonry taxonomy, RISK-EU proposes well-defined fragility curve parameters since they are individually categorized into each masonry material in detail, while the other empirical approaches consider a larger range of masonry classification in general. Consequently, this study also has pointed out that the fragility curve parameters proposed by RISK-UE compared to the others can be more convenient to be used for vulnerability assessment of the taxonomy of old-brick masonry buildings representing the case study building. 


\section{REFERENCES}

[1] Simões, A.G., Bento, R., Lagomarsino, S., Cattari, S. and Lourenço, P.B. Fragility Functions for Tall URM Buildings around Early 20th Century in Lisbon. Part 1: Methodology and Application at Building Level. International Journal of Architectural Heritage (2019), pp.1-24.

[2] Saloustros, S., Pelà, L., Contrafatto, F.R., Roca, P. and Petromichelakis, I. Analytical derivation of seismic fragility curves for historical masonry structures based on stochastic analysis of uncertain material parameters. International Journal of Architectural Heritage (2019), 13(7), pp.1142-1164.

[3] Lagomarsino, S., and Cattari, S. Fragility functions of masonry buildings. SYNER-G: Typology definition and fragility functions for physical elements at seismic risk. Springer, Dordrecht, (2014), pp.111-156.

[4] Lagomarsino, S. and Cattari, S. PERPETUATE guidelines for seismic performance-based assessment of cultural heritage masonry structures. Bulletin of Earthquake Engineering (2015), 13(1), pp.13-47.

[5] Mouroux, P. and Le Brun, B. Presentation of RISK-UE project. Bulletin of Earthquake Engineering (2006), 4(4), pp.323-339.

[6] Hancilar, U., F. Taucer, and G. Tsionis. Guidelines for typology definition of European physical assets for earthquake risk assessment. SYNER-G Reference Report 2 (2013).

[7] Erberik, M.A. Generation of fragility curves for Turkish masonry buildings considering inplane failure modes. Earthquake Engineering \& Structural Dynamics (2008), 37(3), pp.387-405.
Porter, K., Kennedy, R. and Bachman, R. Creating fragility functions for performarce-
based earthquake engineering. Earthquake Spectra (2007), 23(2), pp 471-489.
Jaiswal, K. Wald, D. and D'Ayala, D. Developing empirical collapse fragility functions for
global building types. Earthquake Spectra (2011), 27(3), pp.775-795.

[10] Sarabandi, P., Pachakis, D., King, S. and Kiremidjian, A. Empirical fragility functions from

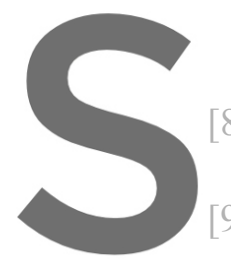

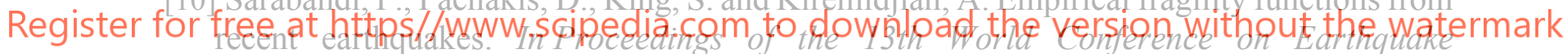
Engineering, Vancouver, BC, Canada. Paper (2004) (No. 1211).

[11] Demiriogiu, K., Gonen, S. and, Soyoz, S. Performance Evaluation of a Historical Brick Masonry Building Using Linear and Nonlinear Analyses. 13th International Congress on Advances in Civil Engineering September 12-14 (2018).

[12] Demirlioglu, K., Gonen, S., Soyoz, S. and Limongelli, M.P. In-Plane seismic response analyses of a historical brick masonry building using equivalent frame and 3D FEM modeling approaches. International Journal of Architectural Heritage (2020),14(2), pp.238-256.

[13] Magenes, G., and G. M. Calvi. In-plane seismic response of brick masonry walls. Earthquake Engineering \&Structural Dynamics (1997), 26 (11):1091-1112.

[14] Norme Tecniche per le Costruzioni (NTC 2008). 2008. Technical standards for Buildings D.M. Suppl. ord. $n^{\circ} 30$ alla G.U. n.29. Roma, Italy: Gazzetta Ufficiale (2008).

[15] Norme Tecniche per le Costruzioni (NTC 2018). 2018. Technical standards for Buildings D.M. Suppl. ord. $n^{\circ} 42$ alla G.U. n. 8. Roma, Italy: Gazzetta Ufficiale (2018).

[16] EN 1998-3. 2005. Eurocode 8: Design of structures for earthquake resistance Part 3: Assessment and retrofitting of buildings. European Committee for Standardization (2005). 
[17] Vamvatsikos, D. and Cornell, C.A. Incremental dynamic analysis. Earthquake engineering \& structural dynamics (2002), 31(3), pp.491-514.

[18] Maio, R. and Tsionis, G. Seismic fragility curves for the European building stock. Brussels: JRC Technical Report, European Commission (2015).

[19] RISK-UE. The European Risk-UE Project: An Advanced Approach to Earthquake Risk Scenarios. (2001-2004) www.risk-ue.net

[20] FEMA, (1999). HAZUS99 user and technical manuals. Federal Emergency Management Agency Report: HAZUS 1999, Washington D.C., USA. (1999).

[21] FEMA (2003). "HAZUS-MH Technical Manual", Federal Emergency Management Agency, Washington, DC, U.S.A

[22] Risk yönetimi ve kentsel iyileştirme daire başkanliği deprem ve zemin inceleme müdürlüğü, İstanbul Olasi Deprem Kayip Tahminleri Deprem, (2009). 